\title{
O noso profesor, o noso compañeiro, o noso amigo
}

\author{
Narciso DE GABRIEL \\ Universidade da Coruña
}

\begin{abstract}
I
Herminio Barreiro Rodríguez chegou a Compostela en 1976 para exercer como profesor na sección de Pedagoxía da Facultade de Filosofía e Ciencias de Educación, que tiña escasos anos de vida e procuraba acomodo na vella Fonseca. Eu fun alumno seu desde o primeiro ano e durante tres dos tres e medio en que concentrei os estudos de Pedagoxía.

As súas clases de Teoría da Educación axiña deron que falar, e aos matriculados fóronse sumando, atraídos polo que alí se dicía, compañeiros e compañeiras procedentes doutras facultades: marxistas, leninistas, maoístas, trotskistas, anarquistas ou nacionalistas, que daquela había moito onde escoller. Eran clases maxistrais, tanto pola forma como polo contido. Lémbroo sentado detrás da mesa profesoral, no estrado dunha escura aula, rodeado de libros e de apuntes que daban soporte a un ben tecido discurso. Comezou falando en castelán e rematou facéndoo en galego, a petición dos "ergas", que proliferaban naquel curso.
\end{abstract}

Herminio lía con precisión os textos seleccionados para os seus alumnos: as teses de Marx sobre Feuerbach, a teoría de Althusser sobre os aparatos ideolóxicos do estado, ou algúns anacos d'A escola capitalista en Francia de Baudelot e Establet, coas súas dúas redes de escolarización: a primaria/profesional e a secundaria/superior. Logo comentaba e enriquecía a lectura. Facíao con contundencia e desde unha posición ideolóxica tan sólida como tolerante. Velaí un dos trazos máis singulares da súa personalidade.

Despois viñeron as clases de Historia da Educación, que tiñan un programa máis acoutado. En terceiro curso Grecia e Roma, a Idade Media coas súas universidades, Erasmo, Lutero, Rabelais, Montaigne, Vives, Comenio. En quinto agardábanos Rousseau, a Gran Revolución Francesa, que prometía outras, a creación dos sistemas educativos nacionais, a educación popular, a Institución Libre de Ensino, a Escola Nova, o socialismo, a Segunda República española. O seu principal recurso metodolóxico era o comentario oral e escrito de textos, sobre o que máis tarde escribirá: "Lembrábanos Enrique Tierno Galván, hai non moitos anos, que a lectura debe facerse tal como beben as galiñas: sorber primeiro coa cabeza baixa sobre o texto —embuchar - e meditar despois coa cabeza erguida —engulir."

Do temario de Historia da Educación Contemporánea extraerá materia para as súas investigacións, centradas na llustración, con especial preferencia por Rousseau, na Revolución francesa, na evolución do sistema educativo español e no pedagogo Lorenzo Lu- 
zuriaga, sobre o que fixo a tese de doutoramento e do que lle custará traballo desfacerse. Arredor destes e doutros asuntos escribiu traballos ben construídos e mellor redactados. Cando un os le ten a impresión de estar escoitándoo falar.

Pero quero insistir máis no seu labor docente que no investigador. O propio Herminio concedíalle máis mérito ao primeiro que ao segundo, o que o convertía nun caso certamente atípico dentro da universidade española, que valora o profesorado en función das publicacións, e máis concretamente do medio onde aparecen, sen tomar en consideración a dedicación docente, por moito que se predique sobre Boloña e as súas excelencias. Herminio sabíao e non lle importaba. Nunca lle importou nadar contracorrente, aínda que non tiña ningún interese - discreto como era- en que se notase.

Estaba convencido de que a súa palabra desempeñou unha función social máis importante e tivo unha audiencia superior á da súa escritura. Á marxe doutras consideracións, botaba contas e saíanlle os números: no ultimo curso como profesor tivo arredor de 700 estudantes matriculados nunha materia de libre elección. Cantos traballos académicos acadan un número de lectores similar?

Os estudantes recoñeceron sempre a súa entrega e valorárono como un dos mellores profesores. Son varias as claves que explican este recoñecemento, das que me referirei a tres.

A rigorosa preparación das clases, recollida nuns cadernos que enriquecía cada ano con anotacións procedentes das súas múltiples e diversas lecturas. Antes de cada sesión, concentrábase no despacho, revisaba os apuntes e seleccionaba algún texto para ler e comentar - a última vez que o escoitei ler foi na Coruña, hai uns meses, nun acto en que acompañaba ao seu pai, que estaba a piques de cumprir 100 anos; leunos un texto de María Zambrano que nos fixo revivir a proclamación da Segunda República nas rúas de Madrid-. Nada, pois, de improvisacións, que as leccións maxistrais, reivindicadas tamén polo seu compañeiro de xeración e de troulas, Xosé Luís Méndez Ferrín, requiren un guión ben estruturado.

A xenerosidade para atender os estudantes. 0 seu despacho estaba sempre aberto e recibíaos cun sorriso que convidaba a entrar e a permanecer -sería curioso rexistrar graficamente a reacción do profesorado cando os estudantes chaman á súa porta: posiblemente nos fornecese datos máis produtivos que os de moitas enquisas ao uso-. Nunca taxou o tempo, nin para recibilos e falar con eles, nin para ler e comentar os seus traballos.

Por último, teño para min que se os seus alumnos e alumnas o respectamos e o queremos -e aquí prescindirei do pasado-é porque el tamén nos respectou e nos quixo. A Herminio gustábanlle os rapaces e as rapazas. Gústalle mesturarse e confundirse con eles fóra das aulas. Nas tabernas - lémbroo na da señora Lola, con Daniel, Xaime e quen isto escribe, saboreando unhas xoubas e engulindo un ribeiro que retrospectivamente se nos antolla pouco refinado-, nas cafetarías e nos pubs, falando de todo un pouco, pero máis que nada de política, nas rúas e nas prazas da cidade vella, paseando, e mesmo dando clase na Praza das Praterías, como aconteceu anos atrás durante a mobilización dos estudantes contra a reforma universitaria. 
Tal foi, con moi escasas modificacións, que afectan sobre todo aos tempos verbais, 0 texto que, a petición de Antón Lopo, publiquei en Galicia Hoxe - xornal que desgraciadamente vén de desaparecer, coma outros editados en galego-, titulado "A forza da palabra", o día no que presentaches en Santiago de Compostela Recordar doe, acompañado do teu editor, Manuel Bragado, o teu amigo Luís Cochón e a túa amiga Lupe Gómez. A ti gustárache 0 artigo, tanto que me chamaches por teléfono para confesarme que a súa lectura che estaba a provocar sensacións narcisistas... Así que me pareceu que esta era a mellor forma de renderche homenaxe neste número da revista Sarmiento dedicado á túa memoria.

Falta o remate do artigo, que dicía así: "Hoxe é profesor emérito e de cando en vez exerce como docente. E continúa paseando por Compostela. Se sigue os pasos do seu pai e da súa nai, farao aínda por moitos anos. Trinta polo menos."

Non puido ser. Ao pouco de morrer a túa nai, á que tan unido estabas, houbo que ingresarte no hospital de Santiago, iniciándose así un penoso proceso que concluirá 06 de novembro de 2010 coa túa morte. "Non me queixo. Vivín o que tiña que vivir", dixéchesme sete días antes, cando te visitamos na túa casa María Salvado, que che levou pasteis da Mora, e máis eu, que ía acompañado das poucas filloas que puiden conseguir na Coruña.

08 de novembro enterramos os teus restos en Sisán, convertida en capital de Galicia, en palabras de Xosé Luís Méndez Ferrín. Alí nos congregamos moitos dos teus familiares, amigos, compañeiros, alumnos e veciños, convocados polo cariño que che tiñamos. Algúns mesmo caeron na conta de que te querían moito máis do que sospeitaban, e non faltou quen, acompañado pola orfandade desde a súa adolescencia, se sentiu algo máis orfo a partir dese día. Foi unha tarde chuviosa, desas que che gustaban.

Falaron algúns dos teus amigos de sempre: Ferrín, Luís Cochón e Daniel Pino; Antonio Vara, en representación do profesorado da Facultade de Ciencias da Educación; Xesús Redondo Abuín, compañeiro de militancia comunista; Branca Novoneyra e Lupe Gómez, que nos trouxeron a poesía de Uxío, en quen tiñas o irmán maior; Carlos Baliñas, que nos deixou abraiados cando leu un anaco da carta que lle fixeches chegar en 1958, na que manifestabas o teu desexo de morrer en outubro, ou cando menos en novembro, e os teus fillos David e Sonia, que fixeron súas verbas de Recordar doe.

Logo viñeron outras homenaxes, como a organizada polo Ateneo de Santiago, do que formabas parte, 010 de xaneiro de 2011. Nunca tantas persoas se xuntaran nun acto organizado por esta institución, segundo me manifestaron os seus directivos. Todas elas escoitaron atentas as intervencións de Manuel Vázquez de la Cruz, Xesús Alonso Montero e a miña, pero a quen realmente querían escoitar era a ti, e supoño que foi sobre todo a ti a quen escoitaron. Por certo, como sei que nos últimos anos te afeccionaches ao ordenador - mira que che custou abandonar a vella Olivetti-e a internet, o vídeo deste acto está colgado en Youtube. 
O 17 de febreiro, os teus amigos da Fundación 10 de Marzo, coa colaboración da Universidade de Santiago, a Real Academia Galega, CC.OO-Ensino e o Ateneo de Santiago, convocáronnos de novo no Paraninfo da Universidade. Ademais do reitor, Juan Casares Long, fixeron uso da palabra, administrada por Ricardo Gurriarán, Xosé Luís Mendez Ferrín, Xesús Redondo Abuín, Miguel Pérez Pereira (o seu texto foi lido, ao non poder estar presente por razóns profesionais), Xosé Barral Sánchez e David, o teu fillo.

Nunha data especialmente querida por ti, o 14 de abril, a Universidade de Santiago outorgouche a súa Medalla de Ouro, que recolleron Merche e David (Sonia non puido asistir, e ben que o sentiu, que sigue en Almería, aínda que con esperanzas fundadas de retornar pronto á Terra, mais si o teu irmán Jacinto e a túa irmá Concha, que seguen a coidar dos 104 anos do voso pai). $O$ acto estivo presidido polo reitor, acompañado de Xesús Vázquez Abad, Conselleiro de Educación e Ordenación Universitaria, Manuel Puga Pereira, presidente do Consello Social da Universidade, Xosé Luís Méndez Ferrin, presidente da Real Academia Galega, Lois Ferradás Blanco, decano da Facultade de Ciencias da Educación, Antonio Rodríguez Martínez, director do Departamento de Teoría da Educación, Historia da Educación e Pedagoxía Social, e Vicente Peña Saavedra, que se encargou da laudatio. Todos eles fixeron uso da palabra para loubar, cada un ao seu xeito, os teus méritos como persoa comprometida, como docente, como investigador, como escritor. Tamén houbo música, galega e cubana, a cargo de Uxía Senlle, e distribuíuse entre os asistentes un libriño da túa autoría, reeditado pola Universidade de Santiago, que seguramente sería o escollido por ti, de teres a oportunidade de facelo: Memoria crítica da escola desde a Universidade: historia mínima dun curso especial na USC.

Antes de que remate o ano, ou se cadra a comezos do próximo, está previsto que 0 teu Departamento organice na Facultade de Ciencias da Educación diversas actividades na túa lembranza. Seica ten previsto, entre outras cousas, darlle o teu nome ao Seminario 3 do Departamento. Ese mesmo seminario no que fuches elixido como o seu director, aventura na que te acompañei como secretario-non sen dúbidas, que che fixeron pasar un mal momento, e polas que me desculpo.

Ese mesmo seminario no que, como todos os anos, nos xuntamos Antón, Porto, Uxío, Cid, Vicente, Luís, Loli, Sabela e máis eu para planificar o número 15 de Sarmiento. Por primeira vez en quince anos, ti non estabas, pero asemade estabas máis presente que nunca. Foi unha reunión difícil. Non polo tema do número, que todos e todas sabiamos cal debía ser, senón polo baleiro que se experimentaba.

Na portada deste Sarmiento poderás ver o retrato que che fixo este verán Juan Galache, un dos teus amigos de Covarrubias. Logo veñen os retratos literarios —que iluminan, desde distintos ángulos, diferentes aspectos da túa persoa-, unha fotobiografía, unha escolma dos teus textos e unha relación das túas publicacións.

Incluíndo este meu, son dezasete os textos que publicamos na túa lembranza. David procurou dar vida ao esquema do libro que tiñas previsto escribir sobre a túa traxectoria como docente: "Doce Francia (1965-1967)", "Vivir en Madrid (1967-1976)", "As camelias 
de Fonseca (1976-1979)", "Preto do Camiño Francés (1979-1986" e "Son do Sur (19862006)". Sonia optou por reflectir neses debuxos que tanto che gustaban a forma en que exercías o teu papel de pai-educador. Logo veñen os recordos dos amigos (Carlos Baliñas, Neira Vilas, Alonso Montero, Daniel Pino, Luís Cochón, Miguel Pérez Pereira, Xavier Castro e Carlos Santiago) e dos teus antigos alumnos (Miguel Anxo Santos Rego, José Antonio Caride Gómez, Vicente Peña Saavedra, Felipe Trillo Alonso e Antonio Rodríguez Martínez). Cerra esta sección Aida Terrón Bañuelos, a nosa amiga da Universidade de Oviedo, que dalgunha maneira representa aos moitos compañeiros e compañeiras da Sociedade Española de Historia da Educación que lles gustaría participar nesta homenaxe.

A fotobiografía reflicte momentos e circunstancias da túa traxectoria profesional, escollidos e glosados por Antón e Vicente. Sobrancean as instantáneas que dan fe da nosa andaina colectiva pola xeografía ibérica co gallo dos sucesivos coloquios e encontros organizados pola Sociedade Española de Historia da Educación.

Os once textos que conforman a escolma dos teus escritos inclúen algúns dos temas de investigación máis queridos e frecuentados por ti: a metodoloxía de investigación histórico-educativa, o comentario de textos como recurso didáctico, Rousseau, a Revolución francesa, Lorenzo Luzuriaga, a Segunda República e a educación en Galicia. Deseguido aparecen dous textos de carácter memorialístico, particularmente brillantes, un sobre a escola de Meilide, na que aprendiches as primeiras letras e os primeiros números da man da túa nai, e outro sobre o grupo Brais Pinto e cada un dos seus integrantes. A escolma remata coa entrevista que che fixo Gena Borrajo para Cuadernos de Pedagogía e co texto que liches no acto celebrado en Santiago de Compostela no 2010 para Refundar a esquerda.

Finalmente, recollemos as túas publicacións, clasificadas en libros, colaboracións en publicacións colectivas e artigos e entrevistas, ás que engadimos as teses e tesinas dirixidas. Esta relación bibliográfica foi confeccionada pola túa amiga Isabel Álvarez e por Cristina Cabada Giadás a partir dun arquivo localizado por David no teu ordenador. A relación seguro que non é exhaustiva, mais ti saberás disimular as súas carencias.

Queremos agradecer a todas as editoriais e publicacións periódicas nas que apareceron os teus traballos que nos permitiran reproducilos en Sarmiento, e tamén o apoio das institucións que fixeron posible co seu financiamento a edición deste número: a Consellería de Educación e Ordenación Universitaria, as Universidades da Coruña, Santiago e Vigo, o Departamento de Teoría da Educación, Historia da Educación e Pedagoxía Social da Universidade de Santiago e os grupos de investigación das tres universidades galegas que configuran a Rede RINEF-CISOC, coordinada polo profesor José Antonio Caride Gómez.

Esperando que o traballo realizado sexa do teu agrado, só nos resta despedirnos: ata sempre, Mestre! 